\title{
NOTAS A RESPEITO DA LEGISLAÇÃO BRASILEIRA SOBRE O ESPAÇO RURAL
}

\author{
Maryna Vieira Martins Antunes
}

Universidade Estadual Paulista - UNESP, Programa de Pós-Graduação em Geografia, Presidente Prudente, SP. Bolsista Capes/Proex

\section{RESUMO}

O texto apresenta um debate sobre o tema da legislação sobre o espaço rural, realizado a partir de uma pesquisa bibliográfica e documental. $\mathrm{O}$ objetivo é tratar de alguns pontos da legislação brasileira sobre o espaço rural, tais como: sua delimitação; formas de propriedade, uso e ocupação do solo rural; sobre parte de sua população e de sua integração com as cidades. Desse modo, foi possível apontar as principais características de tais regulamentações e como conclusões pode-se identificar, a partir das fontes pesquisadas, a importância e potencial da discussão sobre a legislação brasileira para algumas reflexões sobre as relações entre campo e cidade.

Palavras-chave: Legislação; Espaço rural; relação cidade-campo.

\section{NOTES REGARDING BRAZILIAN LEGISLATION ON RURAL AREAS}

\begin{abstract}
The text presents a debate on the theme of legislation on rural space, based on a bibliographical and documentary research. The objective is to deal with some points of the Brazilian legislation on the rural space, such as: its delimitation; forms of ownership, use and occupation of rural land; part of its population and its integration with cities. In this way, it was possible to point out the main characteristics of such regulations and as conclusions one can identify, from the sources researched, the importance and potential of the discussion about the Brazilian legislation for some reflections on the relations between field and city. Key-words: Legislation; Rural area; city-countryside relationship.
\end{abstract}

\section{INTRODUÇÃO}

Entende-se legislação como um conjunto de leis, normatizações e regras derivadas do Estado, que garantem o domínio sobre seu território e sua população. No estudo das relações entre o campo e a cidade notamos a importância de se conhecer tais normatizações por implicarem tanto na divisão oficial entre esses espaços quanto no cotidiano de suas populações. $O$ texto que segue trata o tema a partir de uma pesquisa bibliográfica e documental, o objetivo é tratar de alguns pontos da legislação brasileira sobre o espaço rural, sua delimitação; formas de propriedade, uso e ocupação do solo rural; sobre parte de sua população e de sua integração com as cidades.

\section{METODOLOGIA}

O artigo foi elaborado a partir do levantamento bibliográfico de autores e autoras que debatem o tema ou questões relacionadas.
Foram realizados também buscas documentais em fontes oficiais a respeito das leis e decretos estudados, disponibilizados nos sites oficiais do governo brasileiro. Além disso foi realizado o levantamento de dados oficiais dos censos demográficos realizados pelo Instituto Brasileiro de Geografia e Estatística (IBGE) entre os anos de 1950 e 2010.

\section{A legislação sobre o espaço rural no Brasil: alguns exemplos}

Nesta seção apresentaremos algumas das leis e regulamentações sobre o espaço rural, selecionadas por envolver aspectos caros à análise das relações entre campo e cidade, a saber: a lei do perímetro urbano, responsável pela delimitação entre espaço urbano e rural em cada município; o Imposto Territorial Rural, que contribui para regulamentar o uso do solo no espaço rural; a lei da Agricultura Familiar, uma categorização importante de parte da população rural e a lei do Estatuto da Cidade, que procura 
regulamentar no âmbito municipal o uso do espaço urbano abrangendo suas relações com o espaço rural.

\subsection{A lei do perímetro urbano (Decreto-Lei 311, de 1938)}

A delimitação do que se compreende como espaço rural pelo Estado brasileiro advém da Lei do Perímetro Urbano, instaurada durante o Estado Novo pelo Decreto-Lei 311, de 1938. De acordo com suas determinações, cada município é responsável pela demarcação do perímetro urbano, que geralmente está presente na lei orgânica ou no plano diretor dos municípios.

No artigo terceiro é definido o que deve ser compreendido como cidade: "Art. 3ㅇ A sede do município tem a categoria de cidade e lhe dá o nome" (BRASIL, 1938, p. 01). E no artigo número doze, há uma especificação, ainda que muito genérica, das condições mínimas para o reconhecimento de uma cidade: "Art. 12. Nenhum município se instalará sem que o quadro urbano da sede abranja no mínimo duzentas moradias" (BRASIL, 1938, p. 02).

Tal definição de espaço rural consiste, então, em tudo que não se pode considerar urbano, sem que exista inclusive, uma reflexão do que é o urbano na sociedade brasileira. Essa classificação tem sido problematizada por diversos autores, exatamente por desconsiderar alguns critérios importantes como tamanho populacional, ocupação, renda, pressão antrópica e dimensões econômicas, e principalmente, as relações entre os dois espaços (SILVA, 2011).

\subsection{Imposto territorial rural (ITR) (Lei $n$ ㅇ 9.393, de 19 de dezembro de 1996)}

O Imposto Territorial Rural (ITR), como o próprio nome indica, é o imposto cobrado aos que possuem propriedades localizadas nas áreas rurais, ou seja, fora da área delimitada como urbana em cada município, conforme a lei em vigor desde 1996: "[...] § 2ㅇ Para os efeitos desta Lei, considera-se imóvel rural a área contínua, formada de uma ou mais parcelas de terras, localizada na zona rural do município" (BRASIL, 1996, p. 01).

De acordo com Reis (1988), a constituição de 1891, em seu artigo 9o, institui primeiramente no país o Imposto Territorial, sobre imóveis rurais e urbanos, e era competência dos estados decretar as especificações, critérios e efetuar as cobranças. Assim permanecendo até 1961, quando essa responsabilidade foi transferida para os municípios, por meio da Emenda Constitucional n-5, que foi logo derrubada em 1964, pela Emenda Constitucional no 10 que transferiu, dessa vez, a competência para a União, que deveria reverter os recursos para o município em que se localizavam os imóveis (REIS, 1988).

Como a concepção de função social da terra atrelada à propriedade embasa tal tributação, este imposto procura promover a Reforma Agrária e a redistribuição de terras no país, pois "[...] tem o caráter fiscal, para conseguir os recursos necessários à execução da Reforma Agrária e [...] tem o caráter extrafiscal, como instrumento para forçar o proprietário a promover a sua produção" (PIRES et al, 2000, p. 02).

Como pontuam os autores, o Governo, exercendo a função extrafiscal, pode incentivar a construção de benfeitorias e obras de utilidade pública nas propriedades rurais, bem como, estimular a produção e o trabalho de colonização por meio de benefícios fiscais concedidos, desestimular a posse dos latifúndios e combater latifúndios improdutivos devido aos pesados tributos (critério de progressividade no caso de uso inadequado). A lei atribui também imunidade para pequenas glebas, exploradas pela família e que o proprietário não possua outro imóvel (PIRES et al, 2000).

A responsabilidade pela arrecadação, bem como, tributação e fiscalização é da União, conforme consta no artigo 15 da Lei 9.393/1996: "Compete à Secretaria da Receita Federal a administração do ITR, incluídas as atividades de arrecadação, tributação e fiscalização" (p. 05). Sendo assim, no âmbito municipal, como podemos observar, opera dois tipos de tributação: nas áreas rurais o ITR e nas áreas urbanas o IPTU (Imposto Predial e Territorial Urbano), o que pode implicar diretamente na delimitação do perímetro urbano pelas administrações municipais com a intenção de aumentar a arrecadação, por exemplo, uma vez que a arrecadação do IPTU é responsabilidade das prefeituras.

\subsection{Lei da Agricultura Familiar (Lei $n=11.326$ de 2006)}

A população que habita no espaço rural e/ou que desenvolve atividades econômicas nesse espaço, principalmente relacionadas à agricultura e pecuária, é muito diversificada. Há uma série de leis que regulamentam seus direitos 
e deveres em alguns aspectos de uma forma diferenciada aos demais cidadãos que habitam as cidades, devido às condições de vida que também são diferenciadas, como por exemplo, questões relacionadas à previdência social e leis trabalhistas.

A Lei no 11.326 de 2006, ou Lei da Agricultura Familiar, estabelece diretrizes para a formulação de políticas públicas direcionadas à Agricultura Familiar e Empreendimentos Familiares Rurais. Nos termos da lei, os agricultores familiares são os que praticam atividades no meio rural e que atendem os seguintes critérios:

I - não detenha, a qualquer título, área maior do que 4 (quatro) módulos fiscais; II - utilize predominantemente mão de obra da própria família nas atividades econômicas do seu estabelecimento ou empreendimento; III tenha percentual mínimo da renda familiar originada de atividades econômicas do seu estabelecimento ou empreendimento, na forma definida pelo Poder Executivo; (Redação dada pela Lei no 12.512, de 2011) IV - dirija seu estabelecimento ou empreendimento com sua família (BRASIL, 2006 p. 01).

Esta lei nos remete ao processo de redemocratização do País, em meados da década de 1980, e a retomada da organização dos movimentos no campo, tais como: o movimento sindical dos trabalhadores rurais, reunidos na Confederação Nacional dos Trabalhadores na Agricultura - CONTAG, o Movimento dos Trabalhadores Sem Terra (MST), o Movimento dos Pequenos Agricultores (MPA), o Movimento dos Atingidos por Barragens (MAB), os grupos que reúnem seringueiros e outros que integram os chamados povos da floresta. Dessa maneira, é reconhecida, por parte do Estado, uma categoria social que seria foco de políticas públicas específicas nos próximos anos. 0 marco desse reconhecimento é a implantação do Programa Nacional de Fortalecimento da Agricultura Familiar (PRONAF), no ano de 1996 (ALTAFIN, 2007).
Dez anos mais tarde, a Lei 11.326, com vistas na operacionalização das políticas, procura fixar características gerais dessa categoria tão heterogênea. A lei nos permite refletir sobre importantes alterações na formulação de políticas públicas no país e sobre as distintas situações que 0 grupo genericamente denominado de Agricultura Familiar, bem como, de suas funções na sociedade, que podem incluir tanto a produção de alimentos como a preservação ambiental.

1.4. Lei do Estatuto da Cidade (Lei no10. 257, de 10 de julho de 2001)

O Estatuto da cidade (Lei Federal $n^{\circ}$ 10.257 de 11 de julho de 2001), "regulamentou os artigos 182 e 183 da Constituição Federal de 1988 e estabeleceu diretrizes para a execução da Política Urbana" (PAULA et al, 2013, p. 01). A lei objetiva ordenar o desenvolvimento das funções sociais da cidade e da propriedade urbana, entre as suas diretrizes o Estatuto prevê a articulação o planejamento dos espaços urbanos com os rurais: "[...] VII - integração e complementaridade entre as atividades urbanas e rurais, tendo em vista o desenvolvimento socioeconômico do Município e do território sob sua área de influência" (BRASIL, 2001, p. 01).O Estatuto é inovador no sentido de que, tradicionalmente, o planejamento urbano se limitava ao perímetro urbano e sua expansão. Sendo assim, o planejamento no domínio municipal, por meio do Plano Diretor, deve procurar articulação entre as áreas urbanas e rurais.

Os objetivos do Plano Diretor, de uma forma geral, "[...] orientam a coleta, sistematização e análises das informações e a enunciação dos problemas a serem abordados na elaboração de propostas para um novo ordenamento territorial local" (NAKANO et al, 2004 , p. 59). Em relação ao espaço rural essas orientações indicam que o plano deve incluir "[...] as tendências de desenvolvimento das atividades agrícolas e não agrícolas [...] Com relação às atividades produtivas, é importante analisar as formas de organização da produção e dos produtores" (NAKANO et al, 2004, p. 59-60).

Além disso, a articulação entre os interesses rurais e urbanos necessitam a análise das questões políticas, como por exemplo, os diferentes agentes dos dois espaços, como latifundiários, usineiros, a presença de organizações de agricultores familiares, bem como, agentes imobiliários que visam áreas rurais 
para a expansão urbana, ou mesmo a presença de condomínios que podem gerar conflitos em relação aos diferentes usos do solo. Além das questões ambientais, como a localização de importantes recursos naturais ou áreas de tratamento de resíduos sólidos e esgotos (NAKANO et al, 2004).

\section{Atuação do Estado e as relações entre campo e cidade no Brasil}

Mais de 70 anos separam a promulgação da Lei do Perímetro Urbano da Lei da Agricultura Familiar. Nesses anos nosso país passou por profundas crises econômicas e políticas. Durante o Estado-Novo (1937-1945) incentivou-se à urbanização, industrialização e crescimento econômico do país. É um marco na história do planejamento via Estado no Brasil, que a partir desse período, estendendo-se até a década de 1960 , se caracteriza pelo forte caráter desenvolvimentista, em que a modificação da estrutura econômica do país, até então fundamentalmente agrário-exportadora para uma economia urbano-industrial, era uma das principais motivações.

As políticas públicas promovidas pelo Estado brasileiro nesse período e até a década de 1980 se caracterizam, sobretudo, pela centralização dos poderes de decisão na esfera federal, de forma que os estados e municípios eram apenas executores das políticas formuladas pelo governo federal. Dá-se início, nesse contexto, o processo de modernização da agricultura, que alterou a base técnica da produção e as relações sociais no campo. A partir disso, surgem também novas diferenciações entre a população rural, uma vez que tal processo foi altamente seletivo e excludente em relação às regiões brasileiras (focando o sudeste e o sul), aos produtos (exportáveis) e aos produtores (grandes e capitalizados).

Os impactos da modernização da agricultura são estritamente relacionados há alguns problemas urbanos. A modernização da agricultura e a intensificação do processo industrial geram a partir da década de 1970, o que se chama de explosão urbana, pois, com a introdução de novas técnicas na agricultura houve a expropriação de milhares de pessoas que trabalhavam e viviam no espaço rural que se deslocaram para as grandes e médias cidades ou para regiões de fronteira agrícola. Nas cidades, esses trabalhadores foram marginalizados, uma vez que, estas não estavam preparadas em termos de infraestrutura, além do mercado de trabalho não absorver o contingente de migrantes (DORES; ASARI, 2001).

Os dados apresentados no gráfico 01, por exemplo, demonstram a inversão no local de moradia da população a partir dos anos 1960:

Gráfico 01. População urbana e rural no Brasil entre 1950 e 2010 (\%).

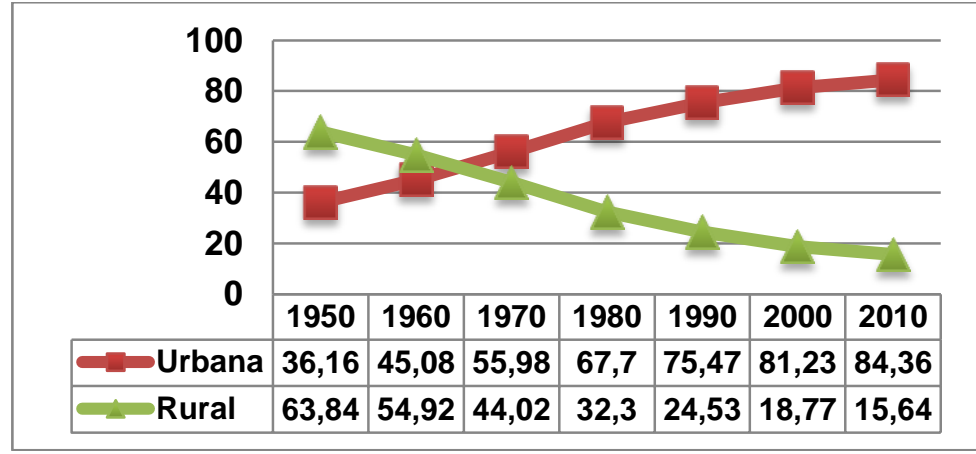

Fonte: Instituto Brasileiro de Geografia e Estatística - Censos demográficos (1950-2010).

Como já apontamos, a população é classificada de acordo com a localização de suas residências (dentro ou fora do perímetro urbano), critério criticado por diversos autores., Veiga (2002), por exemplo, aponta, entre outros fatores, a existência de um grande número de cidades (sedes de município) com até 2000 habitantes, que para o autor não poderiam ser consideradas centros urbano (VEIGA, 2002). O gráfico 02 revela o grande número de municípios com até 50.000 habitantes:

Gráfico 02. Número de municípios de acordo com a população (2010) 


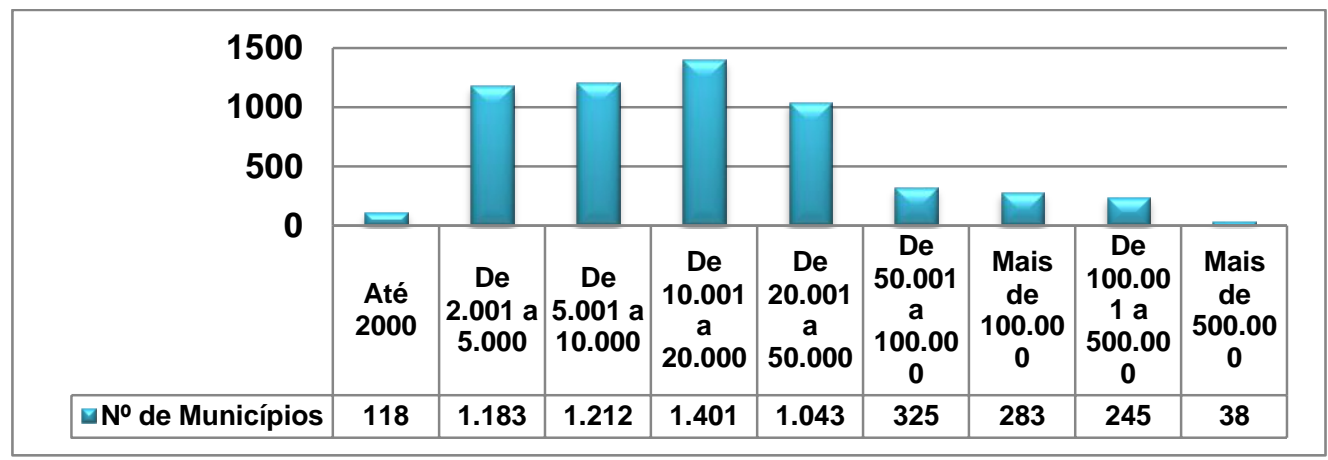

Fonte: Instituto Brasileiro de Geografia e Estatística - Censo demográfico (2010).

Notamos que para uma abordagem do fenômeno urbano no Brasil o critério administrativo, nos revela muito pouco sobre os processos de produção do espaço, sobre "[...] como se ampliam e aprofundam, no mundo moderno, as contradições decorrentes da reprodução da sociedade num momento de generalização da urbanização anunciada pelo desenvolvimento da cidade, isto é com sua 'explosão'"' (CARLOS, 2003, p. 02).

Do outro lado da explosão urbana, há uma população que permaneceu desenvolvendo atividades e vivendo no campo, que se esvazia, enfrentando diversos problemas de infraestrutura, acesso a serviços públicos e elementos para uma melhor qualidade de vida, condições que estão atreladas às estruturas administrativas das cidades (PEGORETTI; SANCHES, 2004).

A partir da década de 1990, com a descentralização das políticas públicas no Brasil, cresce a importância dos municípios na resolução de problemas como os citados acima. Dowbor (2008), explica que com descentralização o poder local, considerado pelo autor não somente como a prefeitura, mas também as organizações de bairro e demais grupos locais, possuam uma dimensão administrativa concreta dos recursos. Entrentando, conforme explica o mesmo autor, enquanto esta pressão explode nos municípios, os escalões superiores "continuam com a sua dramática inoperância, e os mecanismos de financiamento seguem ritmos e burocracias completamente absurdos" (DOWBOR, 2008, p. 09).

Dessa forma, de acordo com Vainer (2002), entendemos que somente uma análise transescalar pode nos ajudar a compreender tais processos. É preciso reconhecer os avanços na participação dos agentes locais nas tomadas de decisão, entretanto, não se pode confundir escala local com administrações locais e é preciso não se esquecer de que ambas não possuem o poder total.

\section{CONSIDERAÇÕES FINAIS}

Diante dessa problemática, concluímos que o tema da legislação brasileira suscita algumas reflexões sobre as relações entre campo e cidade e a legislação municipal, que podem ser aprofundadas a partir de estudos que abordem as maneiras como a temática se desenrola nos municípios a partir de levantamentos in loco, bem como, nos órgãos públicos locais. Gostaríamos de pontuar que, embora muitos elementos não foram contemplados, ficou clara a importância de se conhecer e estudar a legislação sobre o espaço rural tanto no sentido de se apreender as concepções que a embasam quanto em relação às possibilidades e limitações do planejamento.

\section{REFERÊNCIAS}

ALTAFIN, I. Reflexões sobre o conceito de agricultura familiar. Brasília: CDS/UnB, 2007. Disponível em: <http://www.enfoc.org.br/web/arquivos/docum ento/70/ f1282reflexoes-sobre-o-conceito-deagricultura-familiar--- iara-altafin---2007.pdf.> Acesso em: 21 out. 2014.

BRASIL. Lei no 11.326, de 24 de Julho de 2006. Diário Oficial da União, Poder Executivo, Brasília, DF, 25 jul. 2006. Seção 1, p. 01.

BRASIL. Decreto-Lei № 311, de 02 de Março de 1938. Diário Oficial da União, Poder Executivo, Brasília, DF, 7 mar. 1938, Seção 1, p. 4249.

BRASIL. Lei no 10. 257, de 10 de Julho de 2001. Diário Oficial da União, Poder Executivo, Brasília, DF, Seção 1, 17 Jul. 2001, p. 01. 
BRASIL. Lei no 9.393, de 19 de Dezembro de 1996. Diário Oficial da União, Poder Executivo, Brasília, DF, 20 dez. 1996, Seção 1, p. 27744.

CARLOS, A. F. Cidades imaginárias: o Brasil é menos urbano do que se calcula. GEOUSP: Espaço E Tempo (Online), v. 13, p. 179-187, 2003.

DORES, J. L. P.; ASARI, Y. A. A atuação governamental e o processo de migração interna: o caso da Vila Rural da Paz - Rolândia (PR). Geografia. Londrina, v. 10, n. 2, p. 195-210, jul/dez. 2001.

DOWBOR, L. O que é poder local?. São Paulo: Brasiliense, 2008, 75 p.

INSTITUTO BRASILEIRO DE GEOGRAFIA. Censos Demográficos de 1970, 1980, 1991, 2000, 2010. (série histórica). Disponível em: <http://www.sidra.ibge.gov.br>. Acesso em: 13 set. 2015.

NAKANO, K.; NABI, N. I. A.; PINHEIRO, O. M. Plano diretor e as zonas rurais. In. ROLNIK, R. ; PINHEIRO, O. M. Plano diretor participativo: guia para a elaboração pelos municípios e cidadãos. Brasília: Ministério das cidades, 2004.

PAULA, A. S. et al. Dinâmica da ocupação e uso do solo em Londrina (PR): um olhar sobre a interface urbano-rural. Confins. Revue franco-brésilienne de géographie/Revista franco-brasilera de geografia, n. 17, p. 1-16, 2013.

PEGORETTI, M. S.; SANCHES, S. P. A problemática da segregação espacial dos residentes na área rural: uma visão através da dimensão acesso e do sistema de transporte. In: II ENCONTRO DA ASSOCIAÇÃO NACIONAL DE PÓS-GRADUAÇÃO E PESQUISA EM AMBIENTE E SOCIEDADE (ANPPAS), 2004, Indaiatuba. Anais... Indaiatuba, 2004.

PIRES, P. T. L. et al. O imposto territorial rural (ITR) e a sua influência sobre a atividade florestal: um estudo de caso. In: Pesquisa florestal on line, 2000, Curitiba, 2000.

REIS, M. C. D. Imposto territorial rural. Revista da Faculdade de Direito, v. 12 n. 1-2, p. 25-40, jan/dez. 1988.

SILVA, P. F. J. Cidades pequenas e indústria: contribuição para a análise da dinâmica econômica na região de Presidente Prudente-SP. 2011. 282 f. Dissertação (Mestrado em Geografia) - Faculdade de Ciências e Tecnologia Universidade Estadual Paulista, Presidente Prudente, 2011.

VAINER, C. B. As escalas do poder e o poder das escalas: o que pode o poder local? Cadernos do IPUR. Revista do IPUR-UFRJ/DPA, Rio de Janeiro, 2002, p. 13-32.

VEIGA, J. E. Cidades Imaginárias: o Brasil é menos urbano do que se calcula. Campinas: Editores Associados, 2002. 304 p.

Recebido para publicação em 16/08/2018

Revisado em 05/09/2018

Aceito em 20/09/2018 